\title{
Multidisciplinary microscopy course for undergraduate research students in the Natural Sciences
}

\section{Brittani D. McNamee ${ }^{1}$ and James Perkins ${ }^{2}$}

${ }^{1}$ Department of Environmental Studies, University of North Carolina Asheville ${ }^{2}$ Department of Physics, University of North Carolina Asheville

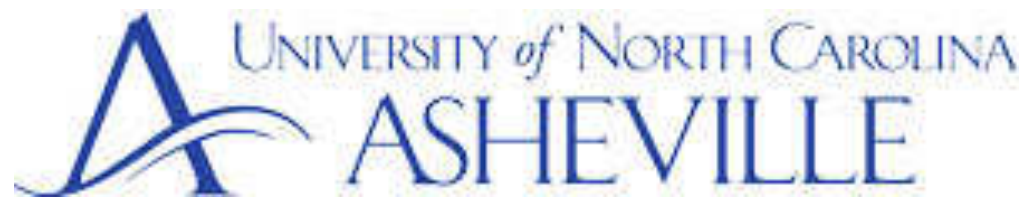




\section{UNCA Microscopy Courses: A Brief History}

2004: SEM purchased through NSF MRI/RUI grant

2005 - 2012: SEM prep and Forensics courses taught by Bill Miller (ENVR) and Herb Pomphrey (BIOL)

2013 - present: "Methods in Microscopy", 1-credit SEM prep course taught in Fall by Dr. Langille (ENVR), Dr. Perkins (PHYS), and/or Dr. McNamee (ENVR)

Fall 2016: "Methods in Microscopy" expanded to 3-credits and include instruction of light microscopy and X-ray diffraction 


\section{"Methods in Microscopy"}

\begin{tabular}{l|l} 
1-credit course & 3-credit course \\
\hline $\begin{array}{l}\text { does not count towards instructor } \\
\text { course load }\end{array}$ & $\begin{array}{l}\text { does count towards instructor course } \\
\text { load }\end{array}$ \\
\hline meet for 3-hr lab for $1^{\text {st }} 6$ weeks & $\begin{array}{l}\text { meet for } 2.5 \mathrm{hr} \text { lecture and } 2.5 \mathrm{hr} \mathrm{lab} \\
\text { each week }\end{array}$ \\
\hline SEM & $\begin{array}{l}\text { SEM and other electron microscopes, } \\
\text { XRD, and light microscope }\end{array}$ \\
\hline $\begin{array}{l}\text { assignments include portfolio, } \\
\text { practicum, and presentation of } \\
\text { research project at UGR symposium }\end{array}$ & $\begin{array}{l}\text { assignments include lab worksheets, } \\
\text { portfolio, practicum, project abstract, } \\
\text { presentation of research given during } \\
\text { Finals }\end{array}$ \\
\hline $\begin{array}{l}\text { 6-9 enrollment with 1 student from } \\
\text { Warren Wilson College }\end{array}$ & 13 enrollment
\end{tabular}




\section{UGR Projects using SEM}

- Identification of minerals in sulfide body within granite host at North Buncombe Quarry in Western North Carolina. M. Daniels and B. Governo (2017)

- Mapping garnet compositions in the Ashe Metamorphic Suite to show garnet thermal history. J. Corradino (2017)

- Growing Silver Nanowires. P. Friel (2016)

- Synthesis and Characterization of Titanium Dioxide Nanoparticles. R. Jacques (2016)

- Mineralogical studies of medium to high grade metamorphic rocks at Mount Mitchell State Park, North Carolina, USA. A. Coburn (2016)

- Mineral phase identification of Hendersonville Gneiss at Chimney Rock State Park, North Carolina. K. Wright (2014) 


\section{Course Assignments}

Calculate optimal resolution at different light wavelengths and accelerating voltages.

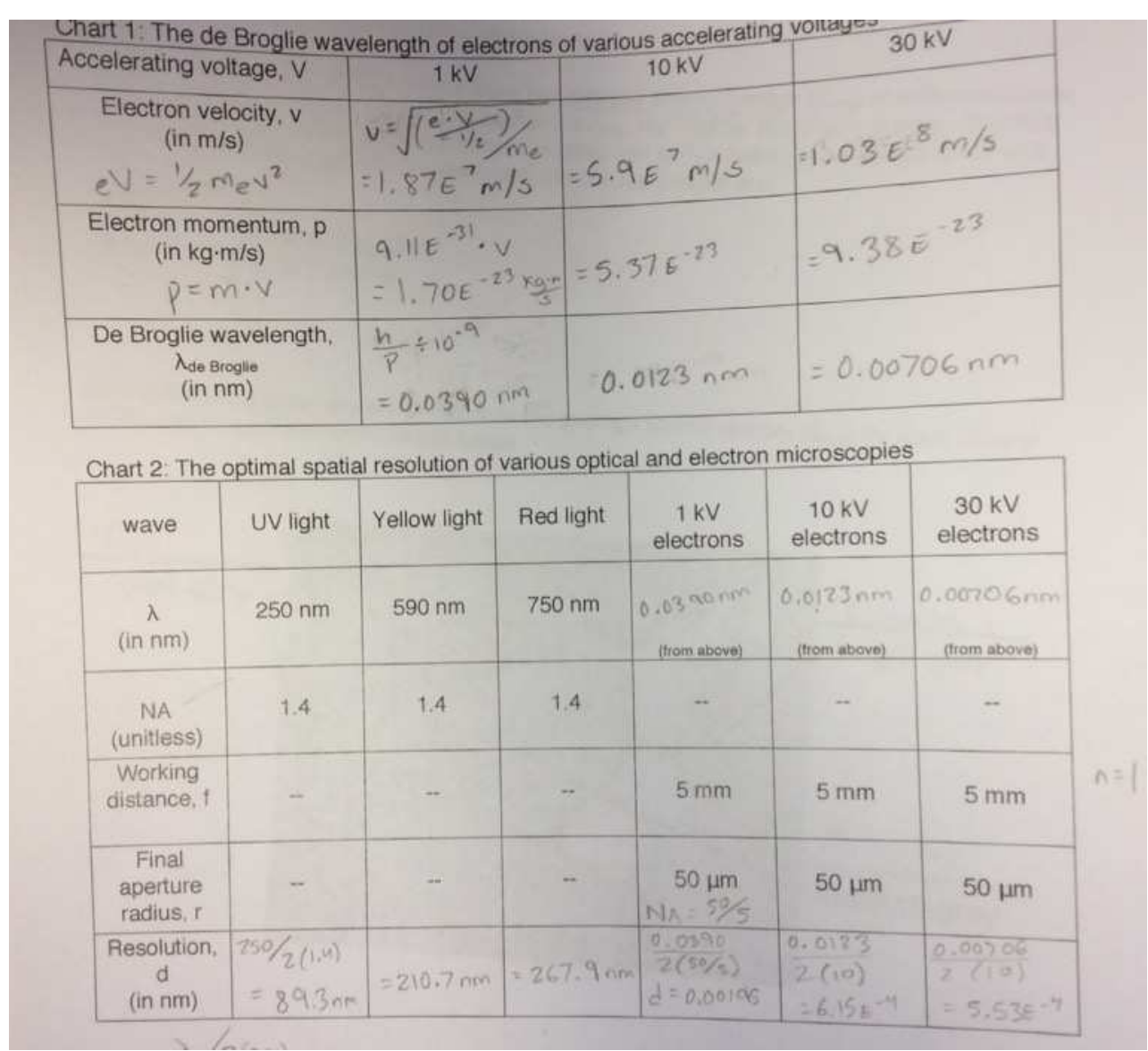




\section{Course Assignments}

Calculate $Z_{\text {avg }}$ of different materials in a backscattered electron (BSE) image.

calcite $\mathrm{CaCO}_{3}$

tremolite $\mathrm{Ca}_{2} \mathrm{Mg}_{5} \mathrm{Si}_{8} \mathrm{O}_{22}(\mathrm{OH})_{2}$ talc $\mathrm{Mg}_{3} \mathrm{Si}_{4} \mathrm{O}_{10}(\mathrm{OH})_{2}$

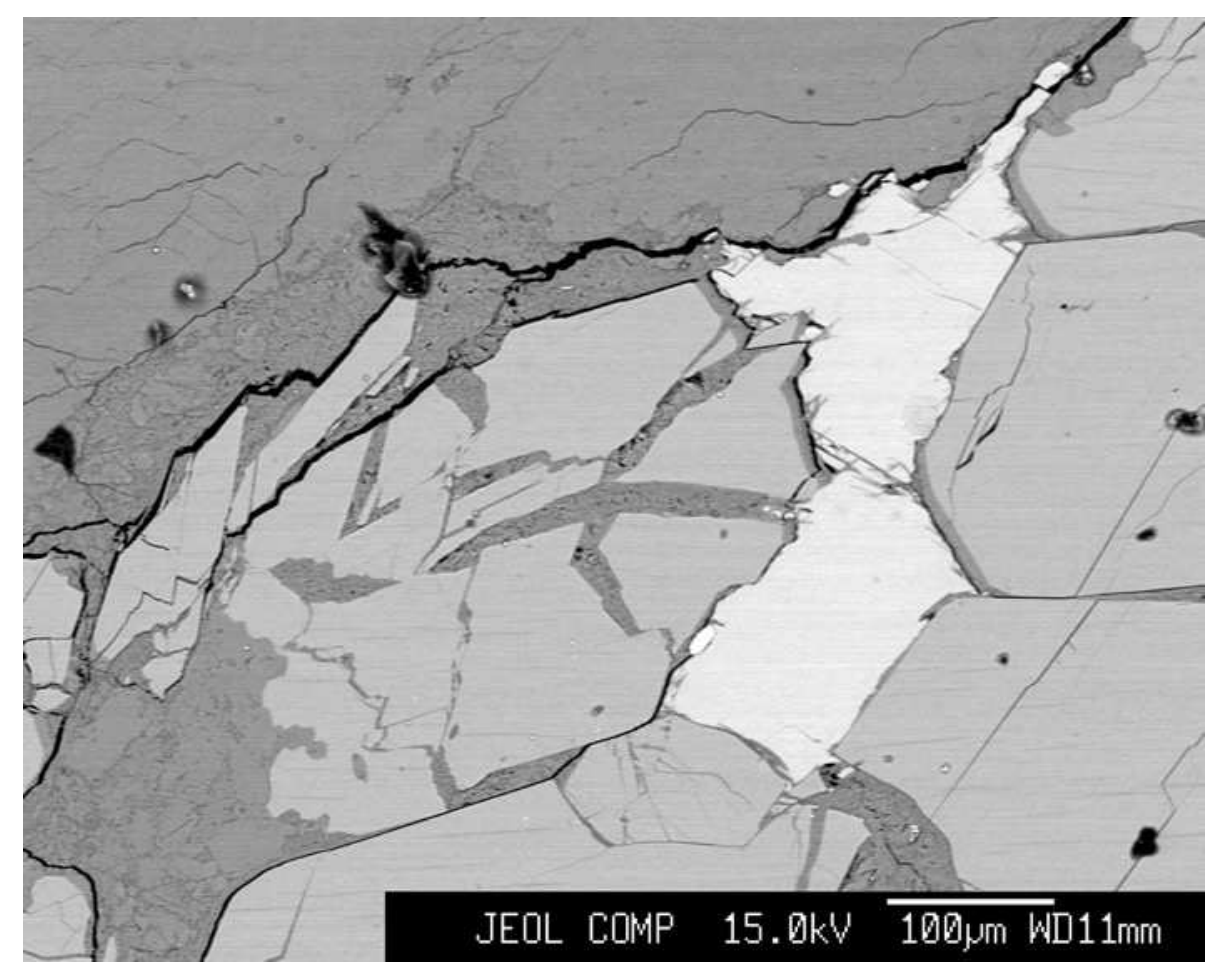




\section{Course Assignments}

Calculate and compare weight percents of elements in minerals (ideal amounts) to observed peak heights in energy dispersive spectra (EDS).
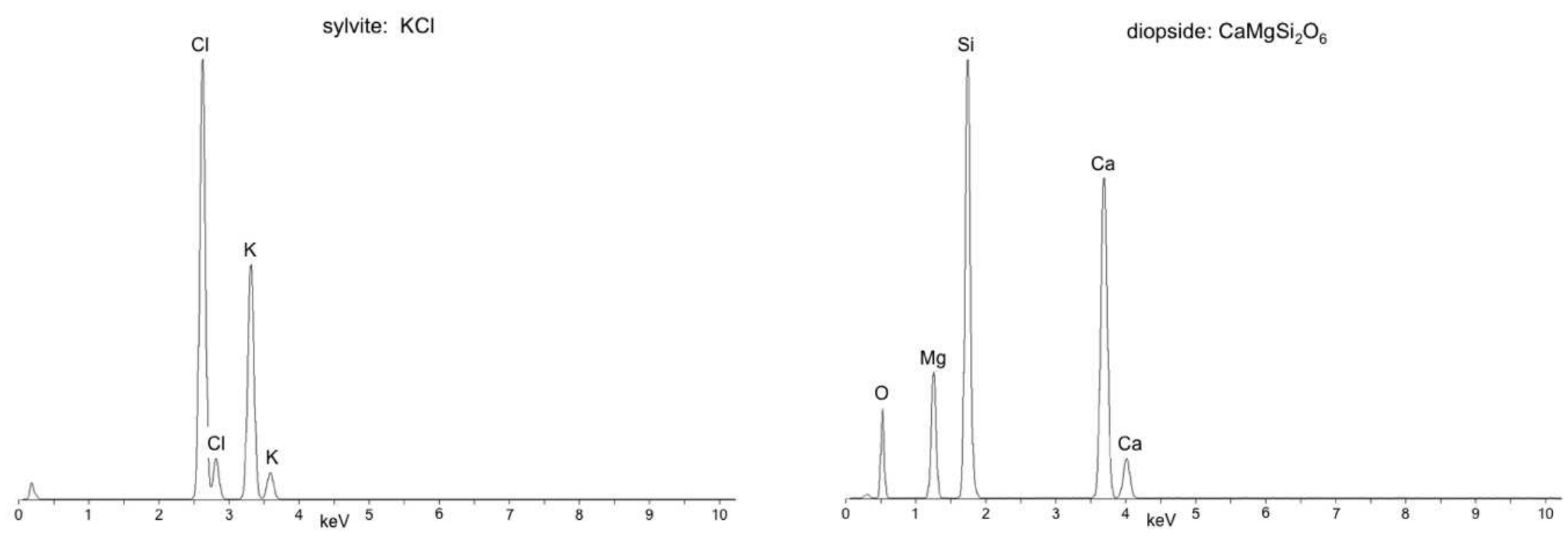

spectra from Mineralogy and Optical Mineralogy textbook DVD by M.D. Dyar, M.E. Gunter, and D. Tasa (2008) 


\section{Course Assignments}

Identify optical properties of quartz and an unknown mineral using a polarized light microscope.
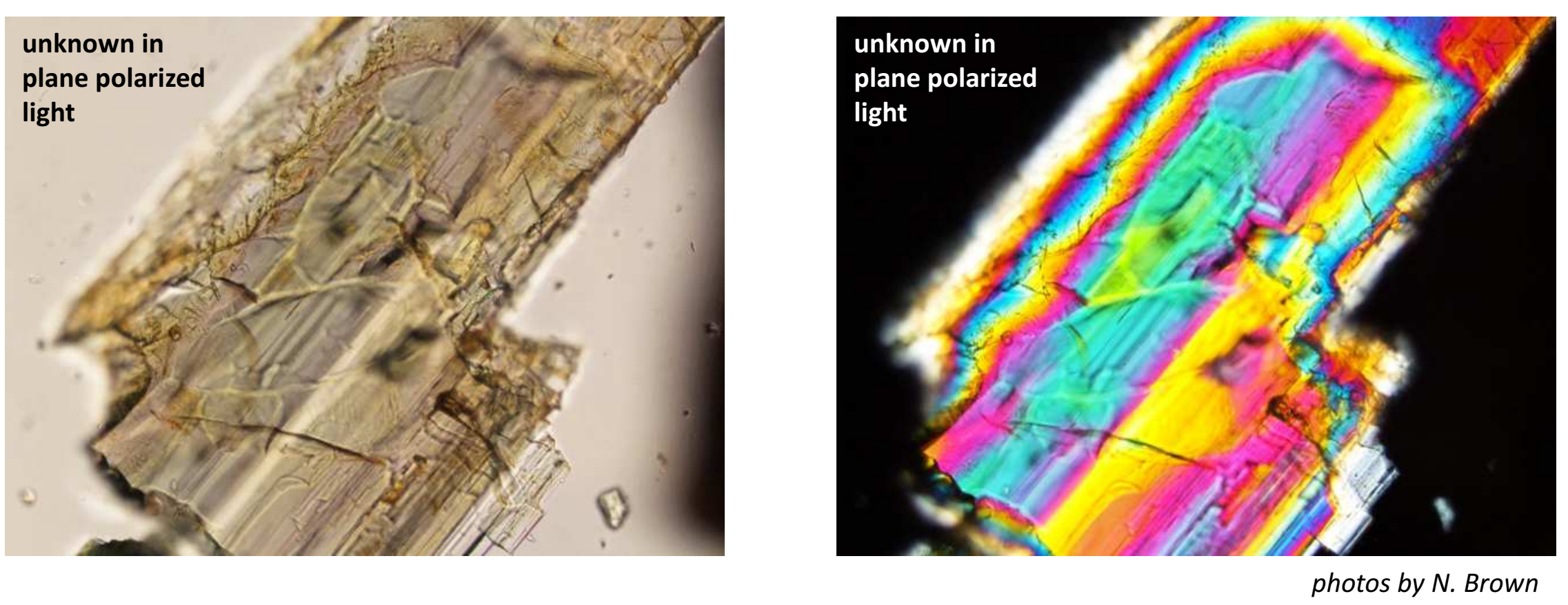


\section{Course Assignments}

Identify mineral phases from X-ray diffraction patterns using WebMineral's online XRD peak database.

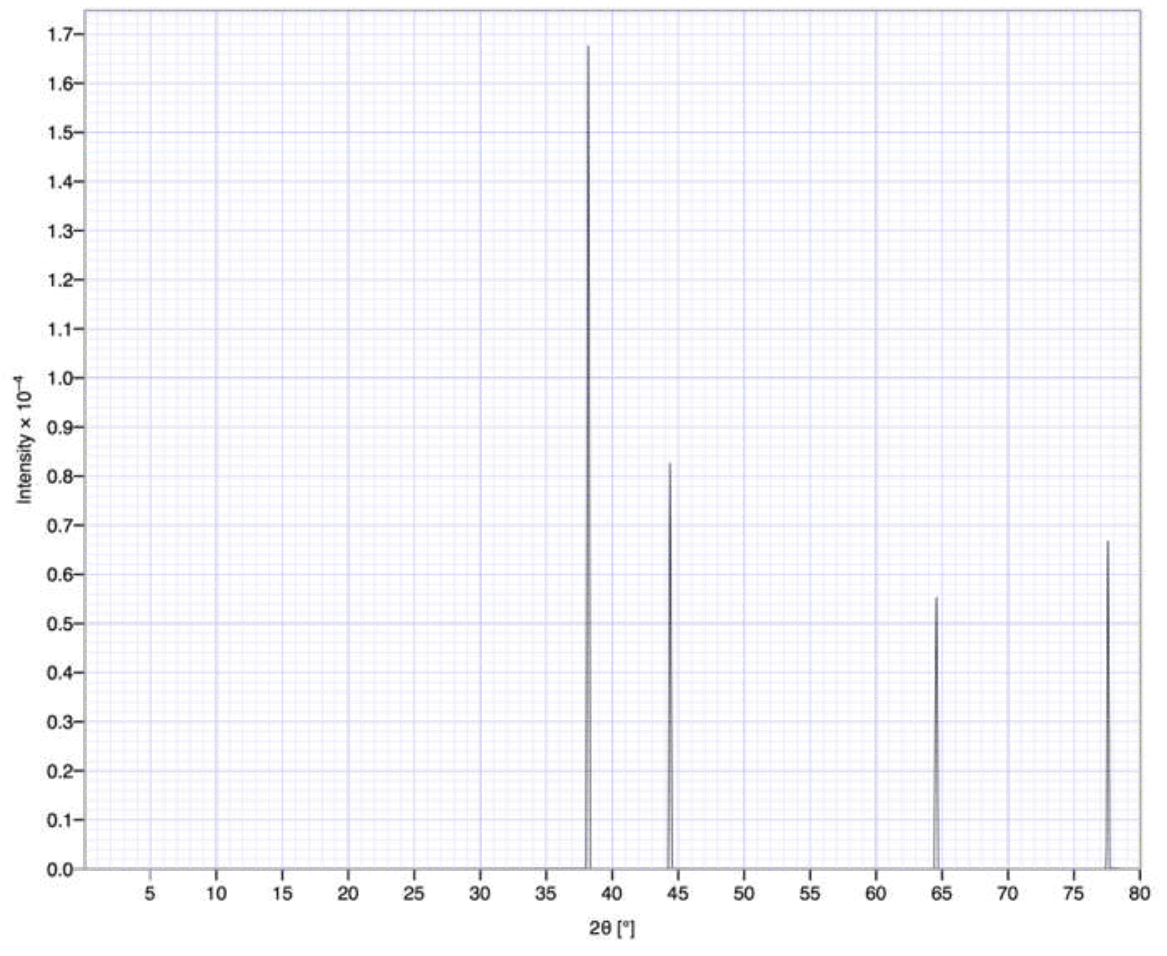




\section{Course Projects}

Scanning electron microscope parameters for imaging insects

T. Elliott (previous semester)
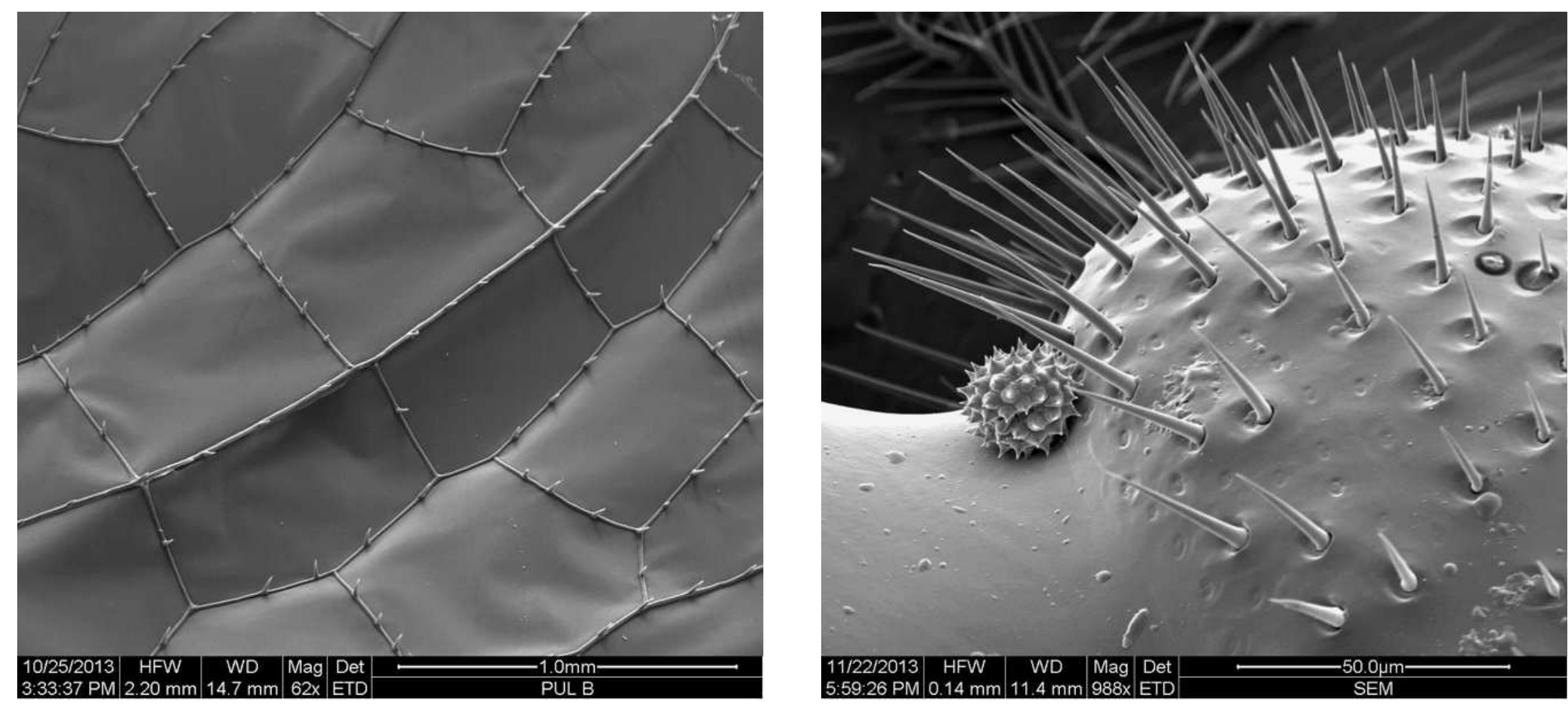


\section{Course Projects}

Identification of unknown blue mineral found in quartzite cliffs of Sauratown Mountains, NC Piedmont

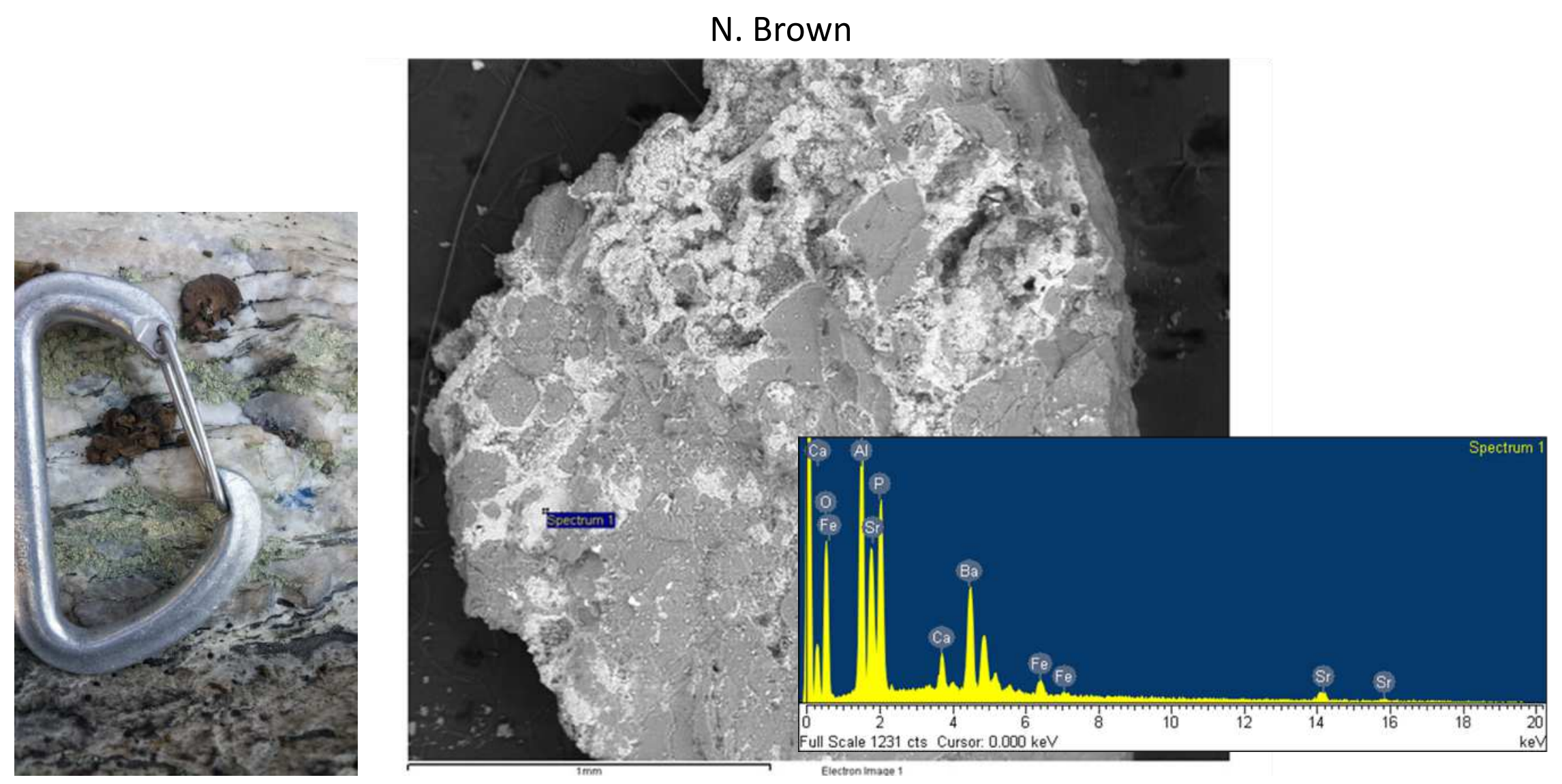




\section{Course Projects}

Chemical analysis of lab sample of a kidney stone

T. Dawson
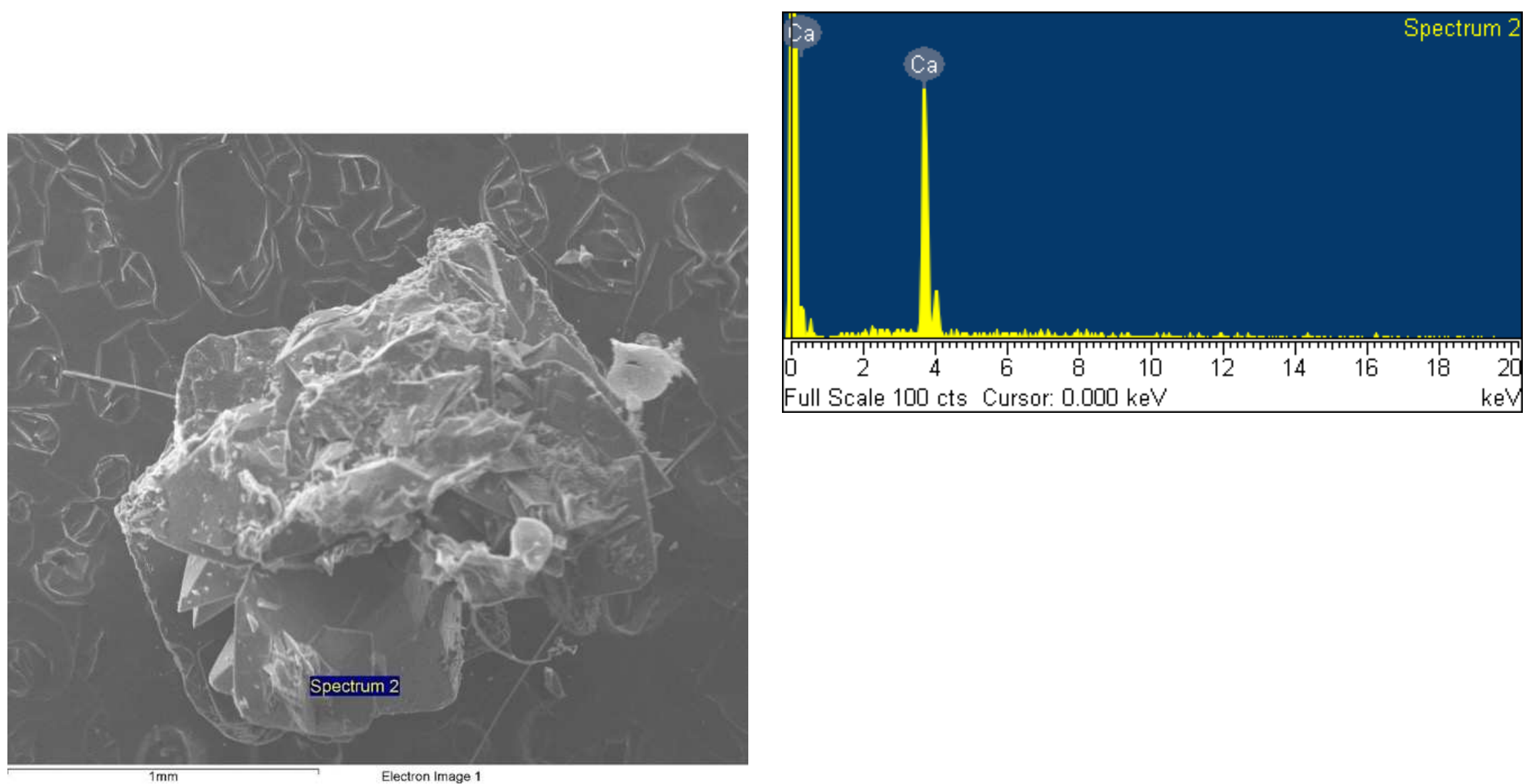


\section{Course Projects}

Cement and aggregate relationships in coal fly ash concrete

B. Strausborger

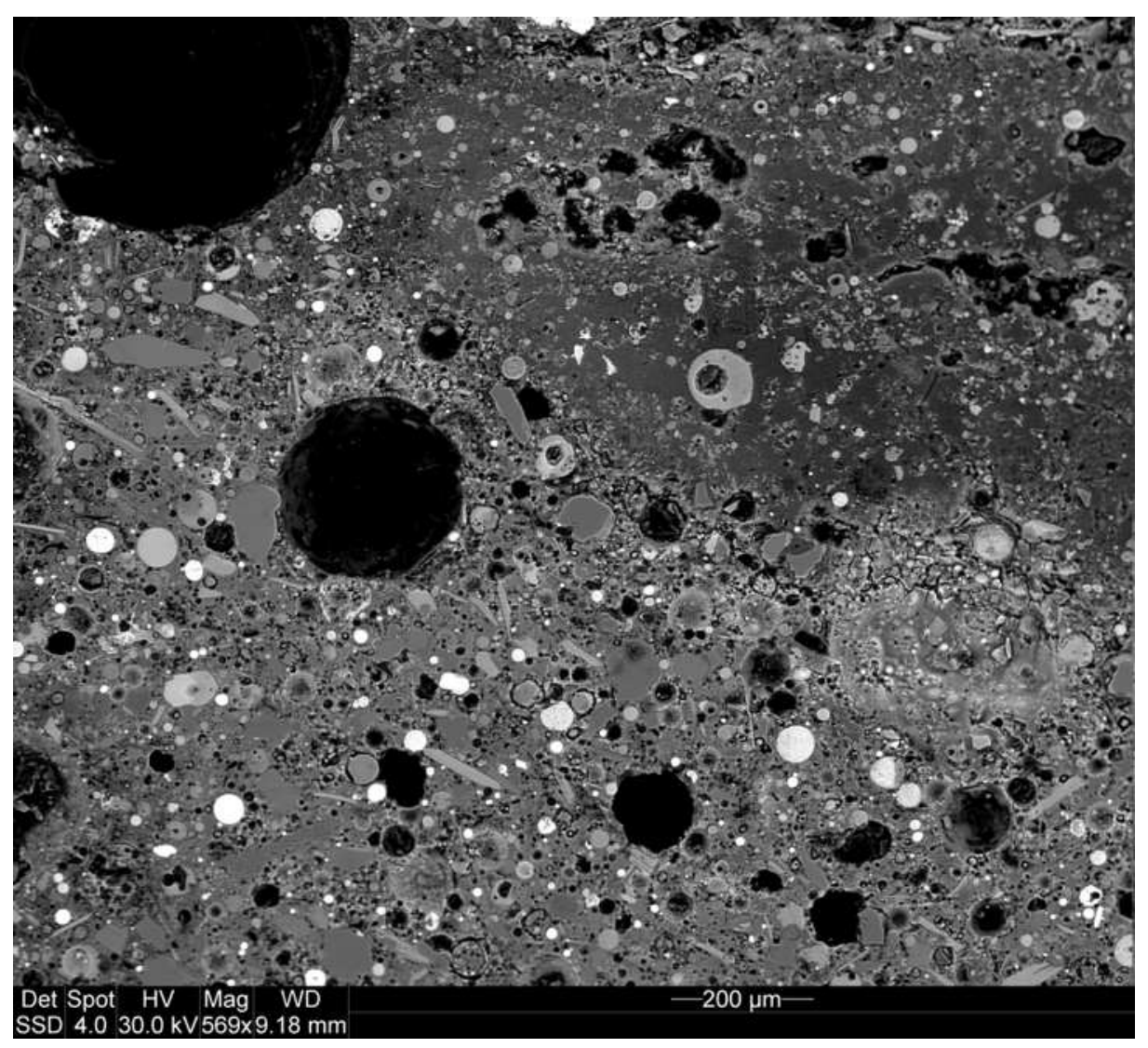




\section{What exceeded our expectations?}

- Explore interdisciplinary uses of each instrument.

- Explore integration of different analyses.

- Encourage students to work on a research project. 


\section{What were the challenges?}

- Increased enrollment created large lab groups or lab groups rotating every other week.

- Increased problems with equipment (or decreased troubleshooting time between users?)

- Time/lab management for 13 students and 2 professors from 3 different departments. 


\section{What do we want to do in the future?}

- Continue the interdisciplinary approach.

- Alternate offering 1-credit option and 3-credit option.

- Tweak course structure by incorporating "Kanban" concepts.

- Make the course sustainable at UNCA. 
